\title{
LEY DE IGLESIAS : ¿LIBERTAD RELIGIOSA O PRESENTE GRIEGO? COMENTARIO DE LA LEY N 19.638 Y SU INCORPORACIÓN AL ORDENAMIENTO JURÍDICO VIGENTE
}

\author{
René Cortínez Castro \\ Abogado \\ Magister en Derecho Público \\ Pontificia Universidad Católica de Chile
}

El 14 de Octubre de 1999, entró en vigencia la Ley N¹9.638, sobre la constitución jurídica de las iglesias y organizaciones religiosas", mal llamada "ley de culto".

Aunque la referida ley reconoce la personalidad jurídica de derecho público de la Iglesia Católica, incluidas las personas canónicas, y la aplicación a su respecto del ordenamiento propio de dicha Iglesia (Derecho canónico) ${ }^{1}$, corrigiendo así uno de los prin-

1 La Ley $N^{\circ} 19.638$, mantuvo el estatuto jurídico de la Iglesia Católica en el derecho chileno, que le reconoce -no otorga- personalidad jurídica de derecho público. Así, el inciso $2^{\circ}$ del artículo 547 del Código Civil, que rige inalterado, desde el $1^{\circ}$ de Enero de 1857 , reconoce la personalidad jurídica de derecho público de "las iglesias" (las distintas subdivisiones de la Iglesia Católica Universal) y "las comunidades religiosas" (las corporaciones y fundaciones religiosas católicas). En su oportunidad la "Comisión Ortúzar", redactora de la Constitución Politica de 1980, al aprobar el actual Art. 19 N6, consignó el siguiente acuerdo de mayoría: "La Comisión resuelve aprobar este precepto (se refiere al Art. $10 \mathrm{~N}^{\circ} 2$ de la Carta de 1925) sin modificaciones, en atención a que él es el producto de un acuerdo adoptado en su oportunidad entre el Gobierno de Chile y la Santa Sede . todas las iglesias y confesiones religiosas tienen personalidad jurídica de derecho público ... Tratándose, sin embargo, de la Iglesia Católica, este reconocimiento ha sido hecho por el propio constituyente de 1925..." (Sesión $132^{\circ}$, de 23 de Junio de 1975). Por otra parte, la doctrina y jurisprudencia reconocen a la Iglesia Católica, y a las personas jurídicas erigidas por ella, como personas jurídicas de derecho público, regidas por el derecho canónico, y ello desde antes de la Constitución de 1833, que la reconocía como religión oficial, y también bajo las Constituciones de 1925 y 1980. Los Tribunales de Justicia han resuelto que "en la actualidad, la iglesia Católica tiene en la República la misma situación jurídica de que gozaba durante la Colonia al producirse la independencia de la nación y después durante la vida independiente de Chile; o sea, es una persona jurídica de derecho público que, conforme al artículo 547 del Código Civil, se rige por leyes y reglamentos especiales. Dichas leyes especiales están contenidas principalmente en el Código de Derecho Canónico..." (Repertorio del Código Civil, Art. 547). Igual doctrina sustenta el Consejo de Defensa del Estado: "...la personalidad jurídica de derecho público no se obtiene en virtud de un precepto constitucional o legal que la otorgue. La de los entes que gozan de ella se da por supuesta en las distintas normas juridicas, tratados y convenios internacionales y documentos oficiales que las mencionan, aceptándose que la personeria de quienes los representan emane de resoluciones o acreditativos otorgados por sus propios órganos. Tal es el caso, por ejemplo, de los Estados, de las distintas Naciones y de algunas instituciones que, por su tradición histórica y su prestigio, se reconocen universalmente, como la Iglesia Católica. Apostólica y Romana y la Cruz Roja Internacional, entre otras ... No cabe duda a este Consejo que la Iglesia Católica, Apostólica y Romana ... goza de una personalidad jurídica de derecho público que no se le ha dado por alguna autoridad civil y que no puede perderla por disposición de ésta." ( Informe N 192 de 25.05.1977). El reconocimiento de la personalidad jurídica de derecho público de la Iglesia católica, y de su ordenamiento jurídico no es un "privilegio" de ésta, sino una consecuencia de las características jurídicas de dicha Iglesia. 
cipales defectos del proyecto ${ }^{2}$, sin embargo, presenta otros que persistieron en el texto promulgado, de los que nos ocuparemos en estas líneas.

\section{CARACTERIZACIÓN DEL FENÓMENO RELIGIOSO}

El Art. $4^{\circ}$ prescribe que "se entiende por iglesias, confesiones o instituciones religiosas a las entidades integradas por personas naturales que profesen una determinada fe". Todas estas realidades son agrupadas bajo el concepto de "entidades religiosas" $\left(\right.$ Art. $\left.5^{\circ}\right)$.

Este concepto, erróneamente interpretado, podría permitir a grupos de naturaleza muy diversa, que nada tienen que ver con el fenómeno religioso, obtener personalidad jurídica, conforme al procedimiento establecido en el Art. 10, con extraordinaria facilidad, ya que sólo exige que se trate de a lo menos dos personas ("personas naturales") que tengan un conjunto de creencias ("fe"), dejando a un lado el aspecto religioso que debe caracterizarlos.

A este respecto cabe preguntarse, ¿están excluidas las actividades, finalidades y entidades relacionadas con el estudio y experimentación de los fenómenos psíquicos o parapsicológicos o la difusión de valores humanísticos o espiritualistas ${ }^{3}$ u otros fines análogos ajenos a los religiosos? ¿se excluyen las sectas satánicas o los cultos mitológi$\cos$ ? ¿y las relativas a seres extraterrestres?

De la interpretación y aplicación, por la Administración del Estado y los Tribunales de Justicia, de esta ley dependerá si grupos y actividades que nada tienen de iglesias y confesiones religiosas encontrarán amparo en sus disposiciones.

El interés por acogerse a las nuevas disposiciones radica en que, las entidades religiosas "podrán solicitar y recibir toda clase de donaciones y contribuciones voluntarias, de particulares e instituciones públicas o privadas y organizar colectas entre sus fieles" (Art. 15) y "tendrán los mismos derechos, exenciones y beneficios tributarios que la Constitución Política de la República, las leyes y reglamentos vigentes otorguen y reconozcan a otras iglesias, confesiones e instituciones religiosas existentes en el país" (Art. 17).

2 Para un resumen de la discusión de la ley, puede consultarse en la revista Mensaje, los Nºs 464 y 473 , asi como la Separata VII, incluida en la Revista Humanitas N99. Enero-Marzo 1998.

3 La Ley Orgánica de Libertad Religiosa, en el Artículo $3^{\circ}$, N² dispone: "Quedan fuera del ámbito de protección de la presente ley las actividades finalidades y Entidades relacionadas con el estudio y experimentación de los fenómenos psíquicos o parapsicológicos o la difusión de valores humanísticos o espiritualistas u otros fines análogos ajenos a los religiosos". Algunas redacciones adoptadas durante la tramitación de la ley reprodujeron esta norma, opción que se desechó para el texto final. 


\section{ENTIDADES RELIGIOSAS: PERSONALIDAD JURÍDICA Y REGISTRO}

El procedimiento para que las entidades religiosas puedan constituir personas jurídicas, en conformidad a la nueva ley, es el siguiente: 1) Acta constitutiva otorgada por escritura pública, suscrita por todos los constituyentes; 2) Inscripción en el registro público, a cargo del Ministerio de Justicia; 3) Transcurso del plazo de 90 días desde la inscripción, sin que el referido Ministerio, objete la constitución, o si se hubiere deducido objeción, ella sea rechazada por los Tribunales de Justicia, y 4) Publicación en el Diario Oficial, de un extracto del acta de constitución.

Las entidades religiosas pueden constituir personas jurídicas, organizándolas en conformidad a la ley en comento (Art. 10). Se trata de "constituir", esto es, establecer, erigir, fundar, una persona jurídica diversa, por tanto no son las entidades religiosas las que se inscriben.

Esta interpretación se ve reforzada por lo dispuesto en las siguientes normas: a) el inciso segundo del Art. $9^{\circ}$, que distingue claramente entre las entidades religiosas y las personas jurídicas que ellas constituyen, al disponer que: "Las entidades religiosas, así como las personas jurídicas que ellas constituyan en conformidad a esta ley, no podrán tener fines de lucro."; b) el Art. 12 , que en su inciso $1^{\circ}$ dispone que "en los estatutos o normas propias de cada persona jurídica que se constituya en conformidad a las disposiciones de esta ley deberán contenerse aquellos elementos esenciales que la caracterizan ..."; c) el Art. 17, al establecer que "las personas jurídicas de entidades religiosas regidas por esta ley tendrán los mismos derechos, exenciones y beneficios tributarios ...", y d) el Art. 20, que reconoce la personalidad jurídica de las iglesias, confesiones e instituciones religiosas que gozan de ella a la fecha de publicación de la referida ley. Si los sujetos de la inscripción en el Registro fueran las entidades religiosas, estas gozarían de doble personalidad jurídica, la que ya poseían y otra, de naturaleza pública, que obtendrían conforme a la nueva ley, situación que resultaría absurda y contraria a derecho.

En consecuencia, se inscriben y obtienen personalidad jurídica, las entidades que organizan, en conformidad a la ley, las iglesias, confesiones e instituciones religiosas de cualquier culto. No corresponde que se inscriban las entidades religiosas propiamente tales.

\section{PERSONALIDAD JURÍDICA Y DERECHO PROPIO DE LAS ENTIDADES RELIGIO- SAS}

El Art. $9^{\circ}$, reconoce la personalidad jurídica de las "asociaciones, corporaciones, fundaciones y otros organismos creados por una iglesia, confesión o institución religiosa", si conforme a sus normas jurídicas propias, gozan de personalidad jurídica, ${ }^{4}$

Esta "personalidad jurídica religiosa" (sic), se acreditará por la autoridad religiosa que las haya erigido o instituido.

\footnotetext{
${ }^{4}$ No precisa la norma si se trata de personalidad juridica de derecho público o privado.
} 
La aplicación de esta norma ofrece las siguientes dificultades:

¿Cómo se acreditará, fehacientemente, el derecho propio de una entidad religiosa, y la facultad de crear personas jurídicas?;

¿Cómo se determinará quién es la autoridad religiosa competente para otorgar la certificación exigida?;

¿Qué debe entenderse por "personalidad jurídica religiosa"?;

¿Cómo se evitará que para eludir las disposiciones del derecho común que rigen la constitución de personas jurídicas sin fines de lucro, así como las disposiciones de la Ley $N^{\circ} 19.638$, se establezca fraudulentamente un derecho propio para gozar de personalidad jurídica? y

La entidad religiosa que ha creado una persona jurídica, ¿debe, a su vez, gozar de personalidad jurídica en el derecho chileno?

El "derecho propio" de lass entidadés religiosaass, àparecee nuevaamenté à própósitó del patrimonio de las personas jurídicas constituidas en conformidad a la Ley $N^{\circ} 19.638$, con dificultades semejantes.

Así, la "adquisición, enajenación y administración de los bienes necesarios para las actividades de las personas jurídicas constituidas conforme a esta ley estarán sometidas a la legislación común." , y "las normas jurídicas propias de cada una de ellas forman parte de los requisitos de validez para la adquisición, enajenación y administración de sus bienes." (Art. 14).

Conforme al precepto transcrito, si una persona jurídica constituida conforme a la ley en comento, desea, por ejemplo, hipotecar un inmueble de su propiedad, deberá acreditar la validez de dicho acto, no sólo al tenor de sus estatutos registrados en el Ministerio de Justicia, sino que también conforme a sus "normas jurídicas propias".

\section{OBTENCIÓN FRAUDULENTA DE PERSONALIDAD JURÍDICA}

En el año 1992, por medio del Decreto Supremo N426, del Ministerio de Justicia, se rechazó la solicitud de concesión de personalidad jurídica presentada por la "Congregación Espiritual Paz y Amor". Se trataba de una agrupación que anteriormente había gozado de personalidad jurídica con el nombre de "Centro Espírita Paz y Amor", la que fue cancelada "después de una amplia investigación, en la cual se acreditó una serie de graves irregularidades cometidas por los guías espirituales de la entidad, Laura Antonia Alcaíno Pozo, apodada "Madrecita Antonia" y su conviviente, el autodenominado Arzobispo, Carlos Opazo Barragán", y que eran las mismas personas que actuaban en la nueva solicitud. El Ministerio de Justicia concluyó que se trataba "de una organización conformada básicamente para explotar la ingeniudad y creencia de la gente en los poderes sobrenaturales que se atribuye Laura Antonia Alcaíno Pozo, apo- 
dada "Madrecita Antonia". ¿Contempla, la nueva legislación, los medios para evitar abusos como éste? ${ }^{5}$

El abogado Humberto Lagos, perteneciente a la Iglesia Evangélica Bautista, afirmó al respecto que "hay una absoluta falta de controles del Estado respecto de lo que es la entidad jurídica. Cualquier grupo no religioso puede disfrazarse de grupo religioso y constituirse: una secta satánica, sin negar que es adoradora de Satanás, puede tener personalidad jurídica hoy con esta ley". ${ }^{6}$

El procedimiento de constitución, aparentemente contempla sólo exigencias de carácter formal (inscripción y publicación), y el Ministerio de Justicia únicamente puede objetar la constitución "si faltare algún requisito" (Art. 11).

¿Podría, el Ministerio de Justicia, "objetar la constitución" porque la solicitante no es una "entidad religiosa"? ¿Podría hacerlo invocando el contenido de los estatutos? El texto no es claro al respecto, pero nos inclinamos por responder afirmativamente, ya que la ley sólo habilita a las entidades religiosas -esto es, a las iglesias, confesiones e instituciones religiosas de cualquier culto- para constituir personas jurídicas, por lo que deben rechazarse las solicitudes que presenten quienes no tienen esta naturaleza.

\section{REGLAMENTOS PARA LA ASISTENCIA RELIGIOSA}

La letra c) del Art. $6^{\circ}$, entrega a la potestad reglamentaria del Presidente de la República, regular "la forma y condiciones de acceso de pastores, sacerdotes y ministros del culto, para otorgar asistencia religiosa en recintos hospitalarios, cárceles y lugares de detención y en los establecimientos de las Fuerzas Armadas y de las de Orden y Seguridad".

Esta disposición, de dudosa constitucionalidad, plantea numerosas interrogantes. ¿Todas las iglesias deberán contar con una institución semejante al Vicariato Castrense, cuya regulación acordó el Estado de Chile con la Santa Sede?, de ser así ¿con quienes pactará el Estado?, ¿ingresarán a los hospitales todos los ministros del culto que lo soliciten, o sólo aquellos cuya presencia sea requerida por los enfermos?, ¿pueden realizarse actividades de proselitismo religioso al interior de las cárceles y establecimientos de carácter militar, aunque los internos no lo soliciten?

5 El profesor Jorge Precht Pizarro, ha propuesto modificar la Ley $N^{\circ} 19.638$ en el sentido que: "no debe darse extraterritorialidad a la personalidad de derecho público que se reconoce. Chile suscribió el 24 de Mayo de 1984, en La Paz, una Convención Interamericana sobre Personalidad y capacidad de Personas Jurídicas en el Derecho Internacional Privado, cuyo artículo $7^{\circ}$ dice: "Cada Estado parte y las demás personas juridicas de derecho público organizadas de acuerdo con su ley, gozarán de personalidad jurídica privada de pleno derecho y podrán adquirir derechos y contraer obligaciones en el territorio de los demás Estados Partes, con las restricciones establecidas por dicha ley y por las leyes de estos últimos en especial en lo que respecta a actos jurídicos referentes a derechos reales y sin perjuicio de invocar en su caso, la inmunidad de jurisdicción ". Es evidente -y debe haber un texto claro al respecto- que el reconocimiento de personas juridicas religiosas de derecho público es sólo para efectos de su recepción en el derecho interno chileno.

El Metropolitano, 8 de Julio de 1999, pp. 11. 


\section{MINISTROS DE CULTO}

Una dificultad adicional para el ejercicio, futuro, de la potestad reglamentaria del Presidente de la República supone la facilidad con que, de acuerdo a la ley, puede obtenerse la calidad de ministro de culto.

En efecto, el Art. 13 de la Ley $N^{\circ} 19.638$, dispone que "los ministros de culto de una iglesia, confesión o institución religiosa acreditarán su calidad de tales mediante certificación expedida por su entidad religiosa, a través de la respectiva persona jurídica". ¿Son ministros de culto sólo los "pastores" o "sacerdotes", o también los fieles que predican en las calles? ¿Podría objetarse esta calidad, por la autoridad civil, en caso de abuso?

Extraordinaria importancia tiene esta disposición, ya que la calidad antes indicada permitirá a estos ministros de culto, conforme al referido artículo, tratándose de juicios civiles: 1) rehusarse a declarar ante el juez, invocando el secreto profesional, siendo así, asimilados a los "eclesiásticos" (Art. 360 N¹ del Código de Procedimiento Civil); 2) prestar declaración por medio de informes con lo que se los asimila indiscriminadamente al Arzobispo u Obispos ${ }^{7}$, o ser examinados en su morada (con lo que se los asimila a los religiosos), cuando un juez requiera su declaración (Arts. $361 \mathrm{~N}^{\circ} 1$ y 3 , y 362 del Código de Procedimiento Civil).

La ley procesal civil distinguía estas situaciones personales diversas (eclesiástico, religioso, Arzobispo, etc) dando a cada una el tratamiento correspondiente a sus características (por ejemplo, el secreto de confesión respecto de los eclesiásticos). Por el contrario, la ley en comento, al definir el estatuto de estos nuevos ministros de culto se ha remitido, sin efectuar diferenciación alguna, a las disposiciones anteriores, que sí las hacen.

La técnica legislativa utilizada obliga a preguntarse, si el ministro de culto puede decidir arbitrariamente en que forma prestará declaración (así, por ejemplo, podría escoger declarar por informe, amparándose en la disposición que favorece a los Arzobispos y Obispos), o si más bien, corresponde al tribunal de la causa determinar cuando un ministro de culto debe ser asimilado, por analogía, al "eclesiástico", al "religioso" o al "Arzobispo", conceptos que la ley civil adoptó del Derecho Canónico.

En materia penal, los referidos ministros de culto son asimilados, conforme lo dispuesto en el Art. 13, al "confesor", y en consecuencia, no están obligados a declarar sobre "el secreto que se les haya confiado" (Art. $201 \mathrm{~N}^{\circ} 2$ del Código de Procedimiento Civil). La extensión desorbitada de este beneficio aparece clara si se considera que tratándose de la Iglesia Católica, no cualquier sacerdote o religioso puede excusarse de declarar invocando esta norma del Código de Procedimiento Penal, sino sólo el "confesor"; en cambio, cualquier ministro de culto podría, conforme a la nueva ley, invocando 
su calidad de tal, pretender rehusar su declaración al juez del crimen, aunque la entidad religiosa que lo acredita no posea una institución semejante al sacramento de la confesión o reconciliación de la Iglesia Católica, y en consecuencia no exista de por medio un "secreto religioso". 8

\section{PRINCIPIO DE IGUALDAD}

El Art. 20, que tiene por objeto reconocer el estatuto jurídico de las iglesias existentes en el Derecho chileno, con anterioridad a la promulgación del proyecto de ley, presenta, también, defectos graves.

La disposición debió indicar nominativamente a las iglesias cuya personalidad jurídica reconocía, o a lo menos mencionar a la Iglesias Ortodoxa y Católica, "y las demás". La redacción adoptada parece no obedecer a ninguna opción de técnica jurídica, sino más bien a consideraciones de orden diverso, para no contrariar a ciertos grupos religiosos. La Constitución española vigente, sin ningún falso pudor, menciona nominativamente a la Iglesia Católica. ${ }^{9}$

El reconocimiento del Art. 20 concluye diciendo: "sin que ello sea causa de trato desigual entre dichas entidades y las que se constituyan en conformidad a esta ley". ¿Qué debe entenderse por "trato desigual"?, ¿constituye una afirmación de que el reconocimiento precedente no vulnera el principio de igualdad?, ¿corresponderá al juez, en cada caso, frente a una controversia determinar si el estatuto reconocido a las iglesias existentes es o no contrario al principio de igualdad? ${ }^{10}$

El Congreso Nacional optó, contribuyendo aún más a la ambigüedad de la nor$m^{11}$, por utilizar la expresión "trato desigual", con lo que aparentemente no podría existir diferencia alguna.

La Constitución Política de 1980 , en su Art. 19 N², al consagrar el principio de igualdad, proscribe las "diferencias arbitrarias", ya que, lo que se opone a dicho principio son las diferencias o discriminaciones arbitrarias. En caso contrario habría que entender que toda diferencia es contraria a la Constitución, así por ejemplo, hombres y mujeres deberían jubilar a la misma edad; la responsabilidad civil y penal sería exigible

Adicionalmente, el Art. 171 del Código de Procedimiento Penal dispone que quienes están autorizados para negarse a declarar, tampoco pueden ser apremiados para que exhiban o entreguen "objetos o papeles que puedan servir para la investigación"

9 Art. $16 \mathrm{~N}^{\circ} 3$ : "Los poderes públicos tendrán en cuenta las creencias religiosas de la sociedad española y mantendrán las consiguientes relaciones de cooperación con la Iglesia Católica y las demás confesiones"

10

Los defectos de redacción fueron objetados durante la votación de la ley. Así, los senadores Gabriel Valdés y Andrés Chadwick, votaron en contra por tal motivo.

11 Ambigüedad que caracteriza a la ley, y a la que aludió el Arzobispo de Santiago al referirse, en su homilia del 18 de Septiembre de 1999, a "ciertas lagunas e imprecisiones del texto legal, de las cuales también sus autores tienen conciencia". 
en contra de las personas de cualquier edad; deberían suprimirse todos los subsidios y beneficios otorgados por el Estado sólo a algunos y no a todos los ciudadanos, etc.

Esta disposición por su ambigüedad, permitiría sostener, por ejemplo, que todas las iglesias y confesiones religiosas que hasta la fecha se han constituido como corporaciones o fundaciones de derecho privado (personas jurídicas sin fines de lucro), como es el caso de miles de pequeñas iglesias evangélicas, se verían impedidas de gozar de los supuestos beneficios de esta ley, ya que el Art. $20^{\circ}$ dispone que estas "mantendrán el régimen jurídico que les es propio", y si deben mantenerlo ¿cómo podría entonces admitirse que lo cambien?

La defectuosa redacción de las disposiciones de esta ley, en materia de igualdad, aparece también en el Art. $2^{\circ}$, que dispone: "Ninguna persona podrá ser discriminada en virtud de sus creencias religiosas, ni tampoco podrán estas invocarse como motivo para suprimir, restringir o afectar la igualdad consagrada en la Constitución y en la ley".

Como no se empleó el concepto de "discriminación arbitraria", ya asentado en nuestra doctrina y jurisprudencia, podría entenderse que esta disposición contradice la facultad de "observar su día de descanso semanal" ${ }^{12}$, que la propia ley reconce a toda persona. Así, podría alguno sostener que, a un rector de Universidad, le estaría vedado autorizar a los creyentes del judaísmo para no ser examinados en día sábado, ya que estaría "discriminándolos" en virtud de sus creencias religiosas.

Al aprobar la Ley $N^{\circ} 19.638$, pareciera que el legislador olvidó que no toda discriminación es injusta, que el derecho opera sobre la base de discriminaciones ${ }^{13}$, y que muchas veces la justicia se satisface con una discriminación positiva.

En parte, los defectos de la norma, obedecen a que fue copiada de la Ley Orgánica de Libertad Religiosa vigente en España, evidentemente sin tomar en cuenta el contexto legislativo diverso. ${ }^{14}$

Este recurso del legislador nacional a su homónimo español queda claramente reflejado en el Art. 18, tomado de la referida Ley Orgánica ${ }^{15}$, que consagra una discriminación arbitraria - y por lo tanto resulta inconstitucional- entre las personas jurídicas que se constituyan conforme a la nueva ley, y el resto de las personas naturales jurídicas o naturales, que sólo tendrán el plazo de un año para regularizar la situación de sus inmuebles $u$ otros bienes sujetos a registro, que pudiesen figurar a nombre de terceros. En cambio, el plazo contemplado en el derecho común podría extenderse hasta los 10

12 Art. $6^{\circ}$, letra b).

13 Asi, distingue entre cosas y bienes, mayores y menores de edad, capaces e incapaces, etc.

14 En nuestro medio parece ser más conocido el Derecho Eclesiástico de Europa, que el de los países vecinos. Una síntesis, para América Latina, puede verse en el trabajo del Pbro. DON FERNANDO RETAMAL FUENTES, "La Libertad de conciencia y la libertad de las religiones en los grandes sistemas contemporáneos - América latina", publicado en Teología y Vida (P. Universidad Católica de Chile), Vol. XXXVII (1996) pp. 307-339.

Disposición $2^{2}$ Transitoria. 
años (prescripción adquisitiva extraordinaria). Es habitual que las iglesias evangélicas que no han obtenido personalidad jurídica, adquieran los inmuebles en que edifican sus templos, a nombre del pastor o de algún miembro de la comunidad, ellas resultarán perjudicadas.

\section{FERIADOS RELIGIOSOS}

La Ley de Iglesias dispone que la libertad religiosa y de culto significan para toda persona, a lo menos, entre otras, las facultades de "conmemorar sus festividades" y "observar su día de descanso semanal" (Art. $6^{\circ}$, letra b).

¿Cómo debe interpretarse esta disposición? ¿Cada persona, conforme a la religión que profese determinará los feriados de que goza, para algunos el domingo, para otros el sábado, etc?, ¿los empleadores e instituciones de educación deberán adoptar las medidas necesarias para que estos puedan hacerse efectivos? ${ }^{16}$

El Congreso Nacional aprobó recientemente un proyecto de ley que tiene por finalidad eliminar los Ilamados días "sandwich", por medio del "traslado", al día lunes más próximo, de los feriados correspondientes a Corpus Christi, San Pedro y San Pablo, Asunción de la Virgen y Todos los Santos.

La Iglesia Católica consintió respecto de la supresión de los dos primeros feriados, y rechazado expresamente el "traslado" de los demás. ${ }^{17}$

De prosperar esta decisión, en realidad, se suprimen los feriados que la autoridad civil había establecido para la celebración de festividades religiosas, y se crean nuevos feriados de carácter exclusivamente civil, días en los que nada se recuerda, nada se celebra, sólo se está liberado del trabajo por decisión del Estado. ${ }^{18}$

¿Por qué se habla de "traslado de feriados"? ¿Acaso el Congreso Nacional tiene facultad para determinar las fechas en que deben celebrarse las fiestas religiosas?

La determinación de las fiestas religiosas corresponde exclusivamente a la Iglesia respectiva ${ }^{19}$. Si conforme al bien común, el Estado les confiere el carácter de días feria-

${ }^{16}$ En el mes de Diciembre de 1999,la prensa informó que la organización Meli Wixan Mapu habria solicitado al Presidente de la República el envio de un proyecto de ley que declare feriado legal el día 24 de Junio, en el que la etnia mapuche celebra la llegada del nuevo año

${ }^{17}$ En declaración pública de fecha 3 de Septiembre de 1999, el Comité Permanente de la Conferencia Episcopal de Chile expresó: "Tratándose de una fiesta religiosa se atropella al grupo humano que la celebra cuando alguien toma la decisión de trasladar la celebración sin su asentimiento. Pues bien, esto es lo que está ocurriendo con las fiestas religiosas cuyo traslado está siendo decidido sin pedir su acuerdo a quienes representan a los cristianos que las celebran." ( $\left.N^{\circ} 2\right)$.

18 Creando feriados que sólo sean días de descanso, para seguir trabajando ( $y$ ansiar luego el descanso) sólo se inciensa el altar de un ídolo que ningún beneficio es capaz de proporcionar a sus "fieles". Estos nuevos "feriados" nada tienen que ver con la religión, aunque la ley pretenda ponerles sus vestiduras.

19

En nuestro país existen, además de las consideraciones aquí indicadas, otras de carácter jurídico, ya que la Ley $N^{\circ} 2.977$, de 1915 en su artículo $1^{\circ} \mathrm{N}^{\circ} 2$ declara feriados, entre otros, los días 15 de Agosto y $1^{\circ}$ de Noviembre de cada año, y dispone que "estas festividades religiosas podrán ser modificadas por el Presidente de la Repú- 
dos, con ello sólo reconoce la existencia de esta celebración, pero, en ningún caso puede luego "trasladarlos" y pretender que se mantenga su carácter religioso. ${ }^{20}$

Rendir culto a Dios, recordar las acciones de quienes contribuyeron al bien común forma parte de lo anterior. No por azar los chilenos hemos nacido en un país que tiene una historia, una población y una geografía propios. Las fiestas tienen que ver con el pasado, pero también con el presente y con el futuro, con la imagen del país que soñamos para el futuro.

De la experiencia histórica, de encuentros y desencuentros, del reconocimiento de un Ser Superior, de celebrar aquello que nos une e identifica, podemos esperar un país en que exista un verdadero bien común a todos.

No parece coherente la acción legislativa de pretender "trasladar" los feriados religiosos contemplados en la legislación vigente ${ }^{21}$, como lo dispone el proyecto de ley recientemente aprobado por el Congreso Nacional, y al mismo tiempo proclamar el más amplio reconocimiento de la libertad religiosa.

Las dificultades reseñadas serán solucionadas mediante la próxima aprobación, en cada una de las Cámaras del Congreso, de las observaciones formuladas por el Presidente de la República al proyecto despachado por éstas.

En efecto, el 4 de Octubre de 1999, el Presidente Frei envió, conforme a lo dispuesto en el Art. 70 de la Constitución Política, sus observaciones, con el fin de conservar los feriados correspondientes a la Asunción de la Virgen y Todos los Santos. ${ }^{22}$

El Ejecutivo propuso sustituir el artículo único del proyecto aprobado, por el siguiente: "Artículo único.- Trasládanse los feriados correspondientes al 29 de junio, día de San Pedro y San Pablo; 12 de octubre, día del descubrimiento de dos mundos ${ }^{23}$; y el

blica en virtud de concordato con la Santa Sede.". La vigencia de esta ley fue reconocida por el Gobierno de Chile, después de la separación de la Iglesia y el Estado, al ser aplicada por los Presidentes Eduardo Frei Montalva y Augusto Pinochet Ugarte.

${ }^{20}$ En materia de feriados el Congreso Nacional no debe olvidar que existe una productividad y rentabilidad, que nada tienen que ver con los bienes y servicios, y que son imprescindibles para el bien común, son los frutos que nacen de los valores espirituales.

21

La "coherencia" podría derivar de erróneos conceptos. Un destacado dirigente empresarial, defensor de la técnica del "traslado", sostuvo en la prensa que, "Semana Santa es una fecha móvil (sic), por lo cual podemos deducir que cualquier otra realmente podría serlo..." (EI Mercurio, cartas al director, 17 de Septiembre de 1999).

22 Fundamentaba el Presidente de la República su decisión en los términos siguientes: "El Gobierno sin perjuicio de estimar el carácter positivo que representa la propuesta legislativa en su conjunto, considerando el carácter religioso y la costumbre profundamente arraigada en nuestra sociedad, que representan los dos feriados mencionados, considera que no deben ser objeto de traslado". Lamentablemente el Poder Ejecutivo incurrió también en el error de entender que se trata del "traslado" de feriados, perdiendo así la oportunidad de reconocer la autonomía del fenómeno religioso; y tampoco se hizo cargo de los efectos, en esta materia, de la Ley $N^{\circ} 2.977$, de 1915 (ver nota 19).

23 Con ocasión de celebrar los 500 años del "descubrimiento de América", se acuñó la expresión sustitutiva, "encuentro de dos mundos", ¿a qué se refiere la expresión el" descubrimiento de dos mundos"? 
día de la fiesta Corpus Christi, a los días lunes de la semana en que ocurren, en caso de corresponder a día martes, miércoles o jueves, o los días lunes de la semana siguiente, en caso de corresponder a día viernes" ${ }^{24}$

La "solución" precedente mantiene el error conceptual de pretender trasladarferiados religiosos, y además - por un error de redacción- aparece trasladando "el día de la fiesta de Corpus Christi" (sic), en circunstancias que de lo que se trata es de trasladar el feriado civil asociado a la referida celebración católica. ${ }^{25}$

\section{CONCLUSIÓN}

Corresponderá al nuevo gobierno dictar los reglamentos para la aplicación de la Ley $N^{\circ} 19.638$, esperamos que en dicha tarea considere el acervo de nuestro ordenamiento jurídico, en el trato de las iglesias, desde 1925; requiera la asesoría de juristas prudentes, escuche el parecer de las diversas confesiones religiosas y considere la experiencia que en la materia tienen el Ministerio de Justicia y el Consejo de Defensa del Estado. Recomendable será, además, tomar en cuenta el Derecho comparado.

Santiago, Enero 20 de 2000.-

${ }^{24}$ Después de redactado el presente trabajo ambas Cámaras del Congreso aprobaron las observaciones formuladas por el Presidente de la República, convirtiéndose su texto en la Ley $N^{\circ} 19.668$, publicada en el Diario Oficial del viernes 10 de Marzo de 2000

25 Además, como lo sostiene el profesor Sr. Jorge Precht P., si la Conferencia Episcopal de Chile decide trasladar la celebración de Corpus Christi al día domingo, el feriado civil desaparecerá, ya que el proyecto no contempla la hipótesis descrita, esto es, el traslado de feriados que ocurren en domingo. 